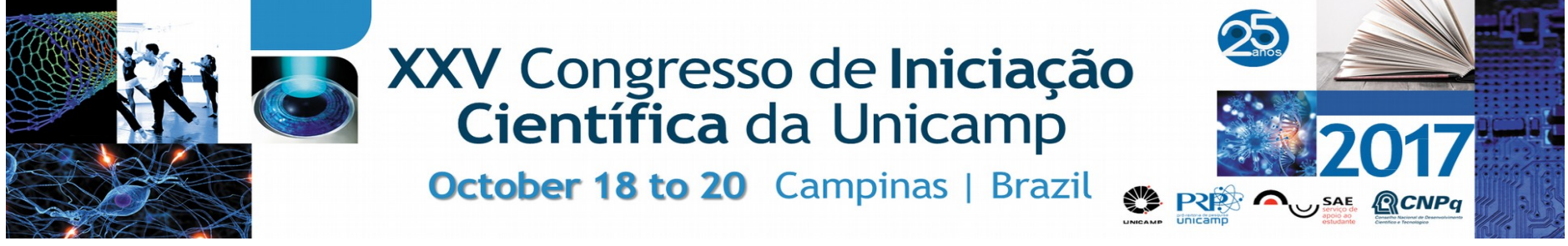

\title{
Mixed Media Picture Book
}

\section{Daniel D. B. Torres*}

\section{Abstract}

The research studied illustration and the history of illustrated books in order to develop and enrich a parallel practical research, which was the production of an illustrated book using mixed media. The book was made with digital drawings and woodblock prints. Everything was authorial, from the script to the drawings.

\section{Key words:}

Picture Book, Illustration, Mixed Media

\section{Introduction}

The main objective was the development of an illustrated book (or picture book) using mixed media, which, at the end, turned out to be digital and woodblock prints. The script and drawings were entirely authorial. Along with the practical production, a theoretical research about history of illustrated books and illustration in general was conducted, in order to improve the quality of the practical results.

\section{Results and Discussion}

The production provided rich results in both practical and theoretical areas. The variety of practical tests allowed to reach the best visual results according to the objective. The digital illustrations (as well as the texts) were printed in special printing paper and the woodblock prints were manually added, resulting the final pages. The book was then manually constructed.

The theoretical research revealed how books and art inserted in books were closely related from the beginning. The illustration has always been an important asset, not only in understanding texts, but also in a decorative way to make books more appealing.
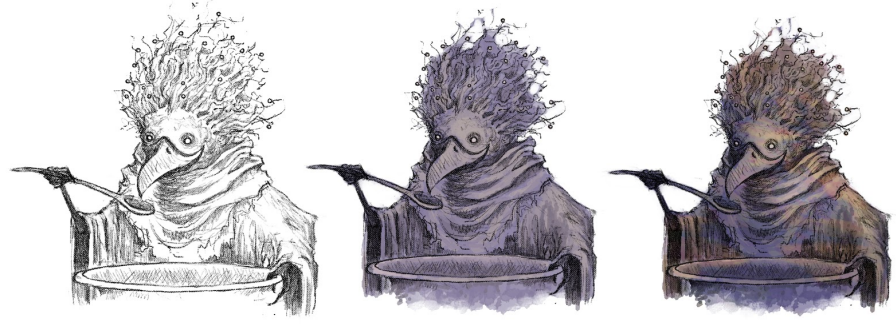

Image 1. Example of one the of the illustrations and the process of colorizing it.

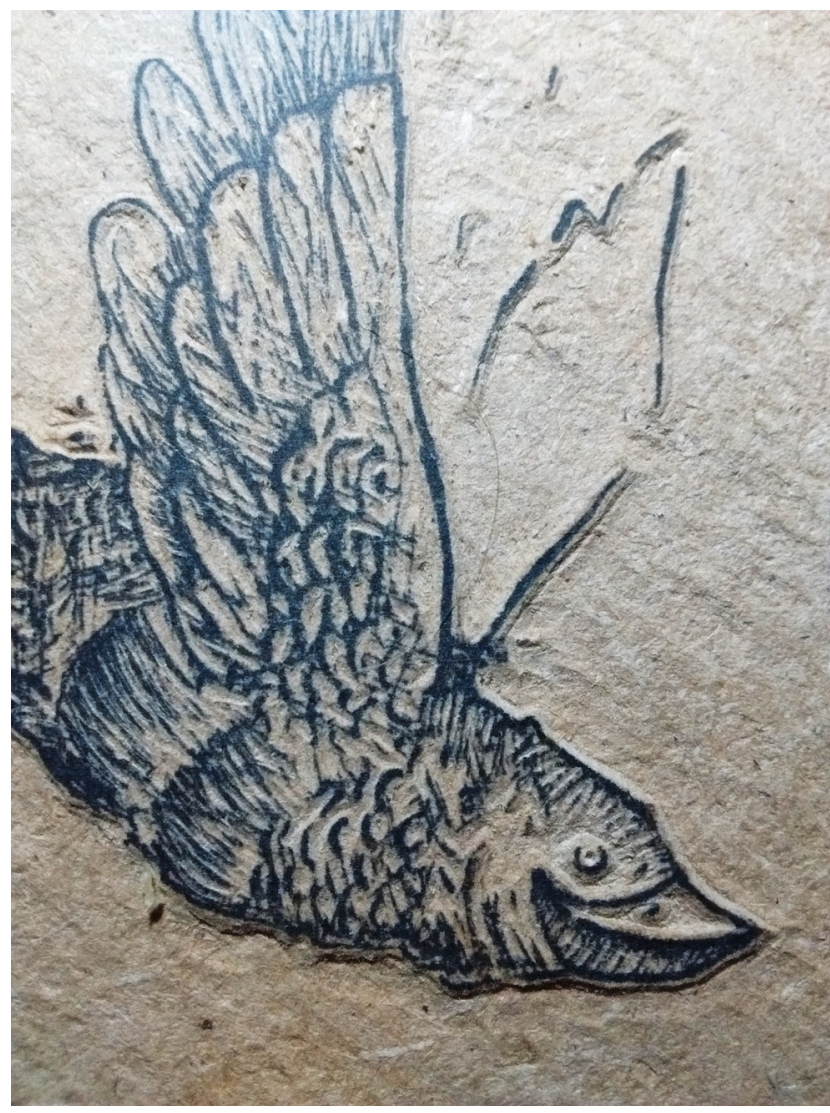

Image 2. Example of one of the Woodblock Engravings.

\section{Conclusions}

The research was a success. The practical results reached the main objective and much was learned regarding the process of drawing and engraving techniques, constructing a picture book, as well as its history in parallel with the history of books in general. 